\title{
The Impact of the Type of Anesthesia to the Occurrence of Postoperative Delirium in Elderly Patients
}

\author{
Trajkova R. ${ }^{1}$, Sholjakova $\mathbf{M .}^{2}$ \\ GCH "8th September" Skopje, R.Macedonia
}

\begin{abstract}
Postoperative delirium is defined as an acute change in the mental condition resulting to an impairment of cognitive functions (orientation, memory and organizational capabilities) inability to maintain concentration and attention problems in perception and changes in the cycle of sleep and wakefulness. The etiology is multifactorial and depends on the clinical features of frequency of the patient, the type of surgery and anesthesia. The purpose of this paper is to show whether there is a difference in the occurrence of postoperative delirium, depending on the type of anesthesia in the first 48 hours at the patients who are over 60 years. Method: The prosperous pilot study is performed on 30 patients aged over 60 years in the period of 3 months. What all patients will be observed is the general health status; the degree of the risk of interventions is determined (ASA status), age, type of anesthesia and the type of operation, as well as the level of education. For the evaluation of the mental status the psychological test Bomke is used (Blesedov test for orientation, memory and concentration). Results: A comparison is being made to the results of the physical and mental health of patients receiving the results of the assessment of the mental status on the day of the surgery and the second day i.e. 48 hours after the surgery. The results suggest that changes in mental status occur in 5 patients of which 3 in the MEA (endotracheal general anesthesia) and 2 RA (regional anesthesia), but the difference is not statistically significant. Conclusion: The occurrence of postoperative delirium depends on the health condition of the patient and the type of surgical treatment and anesthesia. Adult patients are most affected by this complication so you need to carefully evaluate the mental and neurological status because of adequate assessment of the risks and benefits of the planned surgical intervention. The study shows that postoperative delirium occurs less in regional anesthesia then general, but the difference is not statistically significant. It requires a multidisciplinary approach in solving this problem which requires the participation of an anesthesiologist, surgeon, neuropsychiatrist and other experts.
\end{abstract}

Keywords: Anesthesia, cognition, postoperative delirium

\section{The impact of the type of anesthesia on the occurrence of the postoperative delirium in elderly patients}

The modern society faces with a new challenge-aging of the population. The new anesthetic and surgical techniques improved the surgical treatment, reducing the mortality among patients. More elderly patients opt for surgical treatment, on the other hand just in these patients it is diagnosed postoperative delirium as a common form of mental disorder and most common postoperative complication. (1) The postoperative delirium is defined as an acute change in the mental condition resulting in damage of the cognitive function (orientation, memory, organizer capabilities) inability to maintain concentration and attention problems in the perception and influence on the cycle of sleeping and wakefulness. (2)

The delirium can be divided into hyperactive (upset), hypoactive (silent) and mixed. The hypoactive is characterized by the image of reduced mental and physical activity. It is the most common form of delirium in elderly patients and often becomes unnoticed. (3) It is thought that $5-10 \%$ of patients on admission to hospital have a hidden symptom of a disorder of the cognitive functions, while 10$50 \%$ changes occur during hospitalization. $(4,5)$ In some studies even $1 / 4$ of elderly patients who had postoperative delirium die within the first 6 months to a year after surgery. $(6,7)$ The etiology is multifactorial, and the frequency depends on the clinical characteristics of the patient and the surgery.

\section{Objective of the paper}

The objective of this paper is to demonstrate the influence of the type of anesthesia (general or regional) on the occurrence of postoperative delirium in patients over 60 years of age.

\section{Methods}

This study examined 30 patients in a period of 3 months from May to June 2013. All patients on admission were determine their health status, age, ASA status, type of surgery, type of anesthesia, level of education and mental status. From these demographic and clinical data a questionnaire was designed. For the determination of the mental status of the patients the following were used the Blesed test of memory, orientation and concentration (BOMK). The questions of the test are scored and on the basis of the points the cognitive condition is determined, this test was used as a quick and simple way of testing patients. Changes in mental status were evaluated in three periods: before surgery, on the day of surgery and the second postoperative day, i.e. 48 hours.

\section{Results}

The complete survey contains a sample of 30 patients of which 20 were men and 10 women. In the MEA (endotraheal general anesthesia) 16 patients are observed and 14 patients in the RA (regional anesthesia), of which 8 in orthopedic, 5 in urologic and 17 in digestive surgery. 


\section{International Journal of Science and Research (IJSR) \\ ISSN (Online): 2319-7064 \\ Index Copernicus Value (2013): 6.14 | Impact Factor (2015): 6.391}

Blesed's test has points for 6 contents which determine the memory, concentration and orientation of the patient. For every wrong answer there is refusing of 1 point, and more than 10 points indicate the onset of dementing condition (8.9). According to the results, 5 patients deviate from the norm, of which 3 in the MEA and 2 in RA.

The first patient in the MEA on the first postoperative day was easily agitated, distracted, and the memory phase of counting backwards had 12 points. The second and the third in MEA showed minor changes in concentration and memory. The fourth patient showed changes in RA estimated 9 points. The fifth patient in the RA who had 0 points preoperatively, postoperatively there were changes in all content of BOMK, there was no improvement in his second day, almost 25 points and a neuropsychiatrist was consulted.

Demographic structure is comprised of $60 \%$ of patients who were male and $40 \%$ female, with an average value of $72,3 \pm$ 7,2 years. In the age group $50 \%$ of respondents are aged 65 to 74 years, while in the structure according to the education there is a domination of vocational education $56.7 \%$. The analysis of the clinical parameters include ASA score, according to which $76.7 \%$ of respondents are of ASA 2 . According to the type of surgery most usually represented is the digestive pathology in $56.7 \%$ patients, in accordance with the type of anesthesia, $53.3 \%$ of the patients are operated with general anesthesia, while $46.67 \%$ with regional anesthesia.

Table 1: The distribution of socio-demographic and clinical characteristics of the participants. In the study 30 patients are participating

\begin{tabular}{|c|c|c|c|c|c|}
\hline variable & $\mathbf{N}(\%)$ & variable & $\mathbf{N}(\%)$ & variable & $\mathbf{N}(\%)$ \\
\hline \multicolumn{2}{|c|}{ sex } & age & $\begin{array}{c}\min =60 \max =89 \\
\text { mean } \pm \text { SD }(72,3 \pm 7,2)\end{array}$ & \multicolumn{2}{|c|}{ ASA score } \\
\hline male & $18(60 \%)$ & 60- 64г. & $7(23,33 \%)$ & 2 & $23(76,67 \%)$ \\
\hline \multirow[t]{2}{*}{ female } & $12(40 \%)$ & $65-74 \Gamma$ & $15(50 \%)$ & 3 & $6(20 \%)$ \\
\hline & & $75-89 \Gamma$. & $8(26,67 \%)$ & 4 & $3(3,33 \%)$ \\
\hline variable & N (\%) & variable & N (\%) & variable & N (\%) \\
\hline \multicolumn{2}{|c|}{\begin{tabular}{|c|} 
Type of operation \\
\end{tabular}} & \multicolumn{2}{|c|}{ Type of anesthesia } & \multicolumn{2}{|c|}{ Education } \\
\hline digestive & $17(56,67 \%)$ & OEA & $16(53,33 \%)$ & $4^{\text {th }}$ grade & $3(10 \%)$ \\
\hline orthopedics & $8(25 \%)$ & RA & $14(46.67 \%)$ & $8^{\text {th }}$ grade. & $8(26,67 \%)$ \\
\hline \multirow[t]{2}{*}{ urology } & $5(16,67 \%)$ & & & Vocal education & $17(56,67 \%)$ \\
\hline & & & & Higher education & $2(6,67 \%)$ \\
\hline
\end{tabular}

The cognitive status of respondents was analyzed by Blesed's scale that as a criterion for the existence of dementia is taken a score $>10$ in $5(16,67 \%)$ of patients included in the study. The values in Blesed's scale show deviation or disturbance of mental function postoperatively.

Table 2: Number of deviations according to Blesed's scale

\begin{tabular}{|c|c|c|c|}
\hline Score & Preoperative & 1 day & 2 day \\
\hline No changes & $30(100 \%)$ & $25(83,3 \%)$ & $25(83,3 \%)$ \\
\hline $\mathbf{0}-\mathbf{1 0}$ & & $4(13,33 \%)$ & $4(13,33 \%)$ \\
\hline$>\mathbf{1 0}$ & & $1(3,33 \%)$ & $1(3,33 \%)$ \\
\hline Total & & $\mathbf{5 ( 1 6 , 6 7 \% )}$ & $\mathbf{5 ( 1 6 , 6 7 \% )}$ \\
\hline
\end{tabular}

The points more than 10 are related with demention. The average values of the scores of Blesed's scale amounted to $5,4 \pm 4,5$ after the first day of the operative intervention, 6,8 $\pm 10,9$ in the second day of the intervention (Table 3).

Table 3: Points according to Blesed's scale (mean \pm SD) in different time

\begin{tabular}{|c|c|c|}
\hline $\begin{array}{c}\text { Preoperative } \\
(\mathrm{n}=30)\end{array}$ & $\begin{array}{c}1 \text { day } \\
(\mathrm{n}=5)\end{array}$ & $\begin{array}{c}2 \text { day } \\
(\mathrm{n}=5)\end{array}$ \\
\hline No changes & $5,4 \pm 4,5$ & $6,8 \pm 10,9$ \\
\hline
\end{tabular}

The distribution of the transitory symptoms in patients are explained in Table no 4.
Table 4: Friedman ANOVA scale - distribution of symptoms

\begin{tabular}{|c|c|c|}
\hline Score & 1 day & 2 day \\
\hline $\mathbf{0}-\mathbf{4}$ & $1(3,33 \%)$ & $3(10 \%)$ \\
\hline $\mathbf{4}$ & $2(6,67 \%)$ & \\
\hline $\mathbf{7}$ & $1(3,33 \%)$ & \\
\hline $\mathbf{9}$ & & $1(3,33 \%)$ \\
\hline $\mathbf{1 2}$ & $1(3,33 \%)$ & \\
\hline $\mathbf{2 5}$ & & $1(3,33 \%)$ \\
\hline
\end{tabular}

Friedman ANOVAChi Sqr. $(\mathrm{N}=5, \mathrm{df}=2)=2,94 \mathrm{p}=0,23$

Table 5 shows changes in patients depending on the type of anesthesia. A significant deviation is shown in one patient on the second day performed in regional anesthesia.

Table 5: Distribution of BOMK points by type of anesthesia

\begin{tabular}{|c|c|c|c|c|}
\hline \multirow{2}{*}{ Score } & \multicolumn{2}{|c|}{$\mathbf{1}$ day } & \multicolumn{2}{c|}{$\mathbf{2}$ day } \\
\cline { 2 - 5 } & OEA & PA (cI) & OEA & PA (cI) \\
\cline { 2 - 5 } & $\mathbf{( n = 1 6 )}$ & $\mathbf{( n = 1 4 )}$ & $\mathbf{( n = 1 6 )}$ & $\mathbf{( n = 1 4 )}$ \\
\hline $\mathbf{0}$ & $13(43,33 \%)$ & $13(43,33 \%)$ & $16(53,33 \%)$ & $12(40 \%)$ \\
\hline $\mathbf{2}$ & & & & \\
\hline $\mathbf{4}$ & $2(6,66 \%)$ & & & \\
\hline $\mathbf{7}$ & & $1(3,33 \%)$ & & \\
\hline $\mathbf{9}$ & & & & $1(3,33 \%)$ \\
\hline $\mathbf{1 2}$ & $1(3,33 \%)$ & & & \\
\hline $\mathbf{2 5}$ & & & & $1(3,33 \%)$ \\
\hline
\end{tabular}

The type of operations affects the occurrence of postoperative delirium. Changes occur in two operations of thigh fracture, two TOUR interventions and a surgery of malignancy of the rectosigmoid colon. (Table 6) 


\section{International Journal of Science and Research (IJSR) \\ ISSN (Online): 2319-7064}

Index Copernicus Value (2013): 6.14 | Impact Factor (2015): 6.391

Table 6: Number of patients with delirium according to BOMK and type of surgery

\begin{tabular}{|c|c|c|c|c|c|c|}
\hline \multirow[t]{2}{*}{ score } & \multicolumn{3}{|c|}{1 day } & \multicolumn{3}{|c|}{2 day } \\
\hline & $\begin{array}{c}(\mathrm{n}=17) \\
\text { digestive }\end{array}$ & $\begin{array}{l}\quad(n=8) \\
\text { orthopedics }\end{array}$ & $\begin{array}{l}(n=5) \\
\text { urology }\end{array}$ & $\begin{array}{c}(\mathrm{n}=17) \\
\text { digestive }\end{array}$ & $\begin{array}{l}(n=8) \\
\text { orthopedics }\end{array}$ & $\begin{array}{l}(n=5) \\
\text { urology }\end{array}$ \\
\hline 0 & $\begin{array}{c}16 \\
(53,33 \%) \\
\end{array}$ & $\begin{array}{c}7 \\
(23,33 \%) \\
\end{array}$ & $\begin{array}{c}3 \\
(10 \% 0\end{array}$ & $\begin{array}{c}17 \\
(56,67 \%)\end{array}$ & $\begin{array}{c}6 \\
(20 \%)\end{array}$ & $\begin{array}{c}5 \\
(16,67 \%) \\
\end{array}$ \\
\hline 2 & & & & & & \\
\hline 4 & $\begin{array}{c}1 \\
(3,33 \%) \\
\end{array}$ & & $\begin{array}{c}1 \\
(3,33 \%) \\
\end{array}$ & & & \\
\hline 7 & & $\begin{array}{c}1 \\
(3,33 \%)\end{array}$ & & & & \\
\hline 9 & & & & & $\begin{array}{c}1 \\
(3,33 \%)\end{array}$ & \\
\hline 12 & & & $\begin{array}{c}1 \\
(3,33 \%)\end{array}$ & & & \\
\hline 25 & & & & & $\begin{array}{c}1 \\
(3,33 \%)\end{array}$ & \\
\hline
\end{tabular}

\section{Discussion}

The delirium is the most common form of mental disorder in the elderly population and the most common postoperative complication in hospitalized patients. Today the understanding of the pathophysiological mechanism of occurrence is still limited, but there are several hypotheses (10-12). The reduced amount of acetylcholine reduces oxidative metabolism and leads to an increased risk for geriatric population (13). On the other hand the increased stress of surgery and anesthesia increases the amount of cortisol which may be responsible for postoperative delirium (14). High levels of serum alanine phenyl and lower serum levels of tryptophan are also associated with the development of delirium (15).

The clinical picture in these patients indicates a disorder of the entire experience in a large span of confusion, disorganization, hallucinations and delirium. Patients are talking incoherently , the thinking and memory is impaired, disoriented in space and time, their attention is constantly disturbed and are easily distracted, sleepy in the daytime and at night awake and anxious. Among them often occur hallucinations, visual and auditory or a combination of both types that tend to be vivid and frightening. Symptoms are seen in the first or second postoperative day and often at night. They can be quiet and unnoticed, so they are diagnosed as depression. (16,17). The etiology is multifactorial, and in our study we seeked for the causeeffect relationship between age, sex, qualification, type of surgery, type of anesthesia and the appearance of postoperative delirium.

Our results showed that the MEA and RA cause transitory changes in the consciousness and the mental status of the patients. Five patients (17\%) deviate from the norm, of which 3 in the MEA and 2 in RA. The results of our study are similar to other studies centers. The studies that studied the effect of type of anesthesia and the presence of postoperative delirium are not numerous and did not determine the correlation between them. (18) In some studies it is even perceived higher incidence of delirium after spinal anesthesia, but the difference was not statistically significant, most importantly it was determined that the decline in systolic blood pressure $<80 \mathrm{mmhg}$ which is common in spinal anesthesia and is associated with postoperative delirium, that even $90 \%$ of patients with intraoperative time systolic pressure developed postoperative delirium $(19,20)$. In another study it is determined higher incidence of delirium after general anesthesia, but here, as well, we have no significant statistical difference, and the number of patients in the study was small (21). Certain studies have studied the impact of gender and found that signs of postoperative delirium are more likely to occur in women and men performing cognitive decompensation (22).

\section{Conclusion}

The occurrence of postoperative delirium depends on the health condition of the patient and the type of surgical treatment and anesthesia. Adult patients are most affected by this complication, and among them it should be carefully assessed the mental and neurological condition because of an adequate assessment of the risks and benefits of the planned surgical intervention. This study showed that postoperative delirium occurs less in regional anesthesia than in general, but this difference did not show statistical significance. Possible causes are assumed to be the reduced blood pressure, which is subject of patients in the later age, and postoperative relative hypoxia, but these elements should later be explored in more detail. It requires a multidisciplinary approach to solving this problem which requires the participation of an anesthesiologist, a neuropsychiatrist and other professionals (23).

\section{References}

[1] Deiner S, Silverstein JH. Postoperative delirium and cognitive dysfunction. Br J Anaesth 2009; 103 (Suppl. 1): i4l-i46;

[2] Godfrey A. Leonard M, Donnelly S, Conroy M, Olaighin G, Meagher D. Validating a new clinical subtyping scheme for delirium with electronic motion analysis. Psychiatry Res 2010; 178: 186-90.

[3] Godfrey A, Conway R, Leonard M, Meagher D, Olaighin GM. Motion analysis in delirium: a discrete approach in determining physical activity for the purpose of delirium motoric subtyping. Med Eng Phys 2010; 32: 101-110. 
[4] Wice MG, Hilty DM. Delirium (confusion states). U: Psychiatry in the medically ill.Washington, DC: American Psychiatry Publishing, inc. 2002,257-72;

[5] Van der Mast, Roest FJ. Delirium after cardiac surgery: a critical review: J Rsychom Res 1996; 41:13-30;

[6] Elly DW. Delirium in the intensive care unit. Semin Resp Crit Care Med 2001; 22: 115-26.

[7] Mc Cuskler J, Cole M. Delirium predicts 12-mounth mortality. Arch Intern Med 2002; 162: 457-63.

[8] Blessed G, Tomlinson BE, Roth M. The association between quantitative measures of dementia and of senile change in the cerebral grey matter of eldery subjects. $\mathrm{Br}$ J Psychiatry 1968; 114(512):797-811.

[9] Ristic. B, Ignjatovic- Ristic. D, Milicic. B, Obradovic. Z. Faktori koji uticu na postoperacioni mortalitet kod bolesnika sa prlomom kuka. Vojnosanit Pregl 2006; 63 (1) : 49- 53

[10] Anand N, Stead LG. Neuron-specific enolase as a marker for acute ischemic stroke: a systematic review. Cerebrovasc Dis 2005; 20; 2013-9;

[11] Avila J, Lucas JJ, Perez M I sur. Role of tau protein in both physiological and pathological conditions. Physiol Rev 2004; 84;361-84;

[12] Lomas JP, Dunning J.Best evidence topic report: S100bprotein levels as a predictor for long-term disability after head injury. Emerg Med J 2005; 22: 889-91;

[13] Han L, McCusker J, Cole M, Abrahamowicz M, Primeau F, M.Use of medications with anticholinergic effect predicts clinical severity of delirium symptoms in order medical inpatients. Arch Intern Med 2001; 161; 1099-105;

[14] Marcantonio ER, Rudolph JL, Culley D, Crosby G, Alsop D, Inouye SK. Interrelationship between delirium and dementia: serum biomarkers for delirium. J Gerontol A Biol Sci Med Sci 2006; 61A: 1281-6;

[15]Flacker JM, Lipstiz LA. Large neutral amino acid changes and delirium in febrile elderly medical patients. J. Gerontol Biol Sci 2000; 55A:B249-52;

[16] Tune LE. Postoperative delirium. Int Psychogeriatr 1991; 2: 325-32

[17]Lipowski ZJ. Delirium ( acute confusional stales) JAMA 1987; 258: 1789-92

[18]Bilotta F. Early postoperative dysfunction and postoperative delirium after anaesthesia with various hypnotics: study protocol for arandomised trail-the PINOCCHIO trial. Trials 2011; 12170;

[19] Gustafson Y, Berggren B. Acute confusional states in elderly patients treated for femoral neck fracture. J Am Geriatr Soc 1988; 36:525-30,

[20]Edelstein DM. Effect of postoperative delirium on outcome after hip fracture. Clin OrthopRelat Res 2004; 422; 195-200;

[21]Gaudreau JD, Gagnon P. Psychotogenic drugs and delirium pathogenesis: the central role of thalamus. Med Hypotheses 2005; 64; 471-5

[22] Cryns AG, Corey KM, Goldstein MZ. Effects of surgery on the mental status of older persons. A metaanalytic review. J Geriatr Psychiatry Neurol 1990;3: 184-91

[23] Fong HK, Sands L. Leung J. The role of postoperative analgesia in delirium and cognitive decline in elderly patients: A systemic review. Anesth Analg 2006; 102:1255-66 